\title{
Review of the adaptation of skeletal muscle in intermittent claudication
}

\author{
Risha Gohil $^{{ }^{*}}$, Tristan Robert Alexander Lane ${ }^{2}$, Patrick Coughlin ${ }^{3}$ \\ ${ }^{1}$ Academic Vascular Department, Hull York Medical School, University of Hull, Kingston upon Hull, UK \\ ${ }^{2}$ Academic Section of Vascular Surgery, Charing Cross Hospital, Imperial College London, London, UK \\ ${ }^{3}$ Addenbrooke's Hospital, Cambridge, UK \\ Email: risha@doctors.net.uk
}

Received 30 April 2013; revised 30 May 2013; accepted 15 June 2013

Copyright (C) 2013 Risha Gohil et al. This is an open access article distributed under the Creative Commons Attribution License, which permits unrestricted use, distribution, and reproduction in any medium, provided the original work is properly cited.

\begin{abstract}
Background: Despite awareness about the impact of intermittent claudication (IC) on mobility, balance and quality of life; the underlying pathophysiology and alterations in muscle architecture secondary to the disease are often overlooked. This review aimed to summarize the pathophysiological muscle changes present secondary to IC. Methods: The electronic databases, Medline, EMBASE, Cinahl and AMED, were searched for studies from 1967 to August 2011. Search terms included exercise, intermittent claudication and muscle. Studies about IC which were focused on muscle histology, muscle architecture, blood flow or changes with exercise were included. Results: Of 434 studies identified, 135 unique results were found. Only 78 of these were suitable from abstract review, of which 15 were unobtainable and a further nine were identified from hand-searching references. Studies in animal models demonstrated a predominance of type II muscle fibres and an improvement in animal exercise tolerance secondary to training. Exercise alone was never able to improve distances to that of healthy controls, however a lower limb fistula along with exercise did. Lower limb blood flow was demonstrated to be affected regionally, and most evident during exercise with a prolonged return to normal in patients with IC. At a cellular level, the myocytes metabolism increased in those with IC, but returned to normal post-revascularization. Conclusion: Treatment for claudicants includes either revascularization or exercise. Successful revascularization has demonstrated a return to normal muscle metabolism; the underlying physiological improvement secondary to exercise still requires clarification.
\end{abstract}

"Corresponding author.
Keywords: Muscle; Intermittent Claudication; Peripheral Arterial Disease

\section{INTRODUCTION}

Intermittent claudication (IC) is an increasingly prevalent condition in our ageing population, it is characterised by muscular pain on walking, which is alleviated by rest. IC not only affects walking distances, but quality of life and physical functional ability. Exercise training is a recognised treatment for improving quality of life and walking distance. The histological effects of ischaemia on muscle and reversibility of this through exercise have been less explored over the past sixty years.

This review aims to consolidate the knowledge available to allow a better understanding of the effect of IC on muscle architecture, metabolism and how this differs from health; in both animal models [1,2] and patients with intermittent claudication. We hope that a better understanding of the pathophysiology will allow application of this knowledge to clinical practice, and future research.

\section{METHODS}

A systematic review of all available literature was performed. The electronic databases, Medline, EMBASE, Cinahl and AMED, were searched for studies from 1967 to August 2011. Search terms included exercise, intermittent claudication and muscle. Studies about IC which were focused on muscle histology, muscle architecture, blood flow or changes with exercise were included. The searches were performed twice by two people independently with the same search criteria. The searches were then pooled and duplicates removed. As the nature of this review was to identify what is currently understood about the topic of muscle ischaemia in the context of 
peripheral arterial disease, all types of studies were included. The option of only including randomised controlled trials was discarded due to a paucity of data on the subject and the majority of studies having been performed in the 1970s.

All abstracts were assessed, any which did not focus on histological or radiological changes within the muscle at a cellular level, blood flow to the muscle were also removed from the review.

\section{RESULTS}

Of 434 studies identified, 135 unique results were found. Only 78 of these were suitable from abstract review, of which 15 were unobtainable and a further nine were identified from hand-searching references (see Figure 1).

A summary of findings on muscle changes has been included (see Table 1), with the current literature base summarized in the following article.

\section{FIBRE TYPES \& MUSCLE COMPOSITION}

Muscle is composed of two fibre types; I \& II. Type I are slow twitch fibres which are needed for endurance. Type II fibres, fast twitch, are important for short, high endurance activity, and have been reported to have a relatively

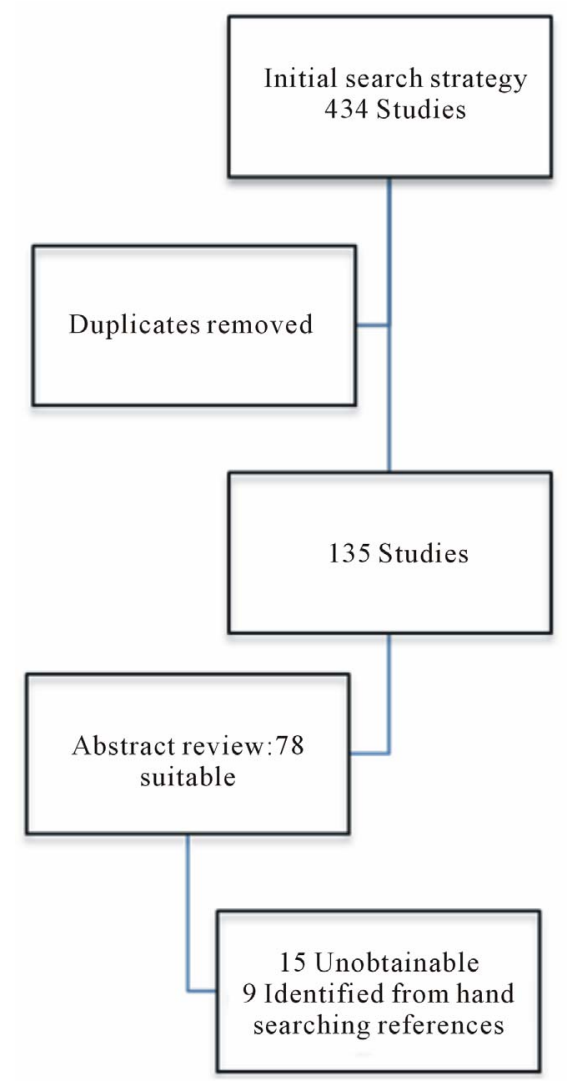

Figure 1. PRISMA chart of studies included. consistent diameter [9,12]; irrespective of the muscle size. Inactivity leads to a change from type I to II muscle fibres with a higher level of atrophy in muscle cells [13] and an alteration in myosin from slow to faster isoforms. (The opposite is true when exercise training occurs, but this finding is not universal [14]).

Ischaemia appears to effect a wide variety of changes, namely fibre atrophy, an alteration in fibre type predominance $[15,16]$ and changes to mitochondrial function and activity [17]. Ischaemic muscle fibre atrophy can result in a $35 \%$ decrease in fibre area, increase in the transcription of specific atrophy related genes, and upregulation of nuclear factor kappa light-chain-enhancer of activated $\mathrm{B}$ cells $(\mathrm{NF} \kappa \mathrm{B})$ activity [18]. NF $\kappa \mathrm{B}$ is a protein associated with DNA transcription. It is most cells and is involved with cellular responses to stress and is involved in regulating immunity. Inhibition of $\mathrm{NF} \kappa \mathrm{B}$ in ischaemic models resulted in lower atrophy specific gene expression and an improvement in muscle fibre cross sectional area [18]. The reduction in fibre size identified in peripheral arterial disease (PAD) has been postulated to be secondary to disuse rather than ischaemia (see Table 2) [7].

\section{TYPE I FIBRES}

Type I fibres use aerobic metabolism to generate ATP efficiently, therefore glucose and glycogen stores are utilised first [19]. This process is dependent on translocation of glucose into the cell via the insulin dependent glucose transporter protein 4 (GLUT 4). Hence a higher concentration of GLUT 4 is seen in type I fibres, and increases with activity [20]. To further support aerobic metabolism, a positive correlation between metabolic muscle rate and lower limb blood flow during exercise has been demonstrated in vastus type I fibres [21]. The increased flow may be secondary to a rise in heart rate and systemic blood pressure, or the increased capillarity of the muscle. Insulin uptake in human muscle positively correlates with the number of capillaries per fibre [22].

\section{TYPE II FIBRES}

Type II fibres, anaerobic in nature, are predominantly glycogen dependant fibres. Type IIB do not alter with exercise training [23], but are positively correlated to pain felt 48 hours post exercise (the point of damage) [24].

Claudicants demonstrate a reduced number of type IIB fibres [25], and an increased capillary supply to IIa fibres and increased oxidative capacity of the affected muscle tissue. These pronounced morphologic and metabolic changes in type II fibres suggest that these fibres are more intensely activated than type I fibres during physical activity [25]. 
Table 1. Summary of literature available on muscle changes in PAD.

\begin{tabular}{|c|c|c|c|c|c|c|}
\hline Study & No. & & Type of PAD & Sample place & Muscle architecture & Other changes \\
\hline $\begin{array}{l}\text { Makitie } \\
1977[3]\end{array}$ & 20 & $\begin{array}{l}\text { SL samples studied } \\
\text { using fresh frozen } \\
\text { cryostat sections }\end{array}$ & $\mathrm{IC}$ & $\begin{array}{c}\text { Gastrocnemius } \\
\text { and rectus } \\
\text { femoris }\end{array}$ & \multicolumn{2}{|l|}{$\begin{array}{l}\text { Neuropathic changes seen: Small group } \\
\text { fibre atrophy } \\
\text { Muscle necrosis and phagocytocsis seen } \\
\text { in } 1 / 3^{\text {rd }} \\
\text { Myofibrillar disorganisation seen in } 2 / 3^{\text {rd }} \\
\text { Number and size of type I fibres } \\
\text { increased with worsening ischaemia. }\end{array}$} \\
\hline $\begin{array}{l}\text { Dahllof } \\
1975[4]\end{array}$ & 6 & 6 patient's with IC & $\mathrm{IC}$ & \multicolumn{2}{|l|}{ Vastus Lateralis } & $\begin{array}{l}\text { Resting muscle glycogen content } \\
\text { improved with glucose feeding } \\
\text { Resting muscle glycogen content } \\
\text { increase associated with increased } \\
\text { work duration on exercise bike. }\end{array}$ \\
\hline $\begin{array}{l}\text { Holm } \\
1975[5]\end{array}$ & 12 & $\begin{array}{l}\text { PAOD samples } \\
\text { taken pre and } 6 \\
\text { months post } \\
\text { operatively }\end{array}$ & $\begin{array}{l}\mathrm{IC}, 2 \text { with } \\
\text { gangrene }\end{array}$ & Not stated & $\begin{array}{l}\text { Pre operatively, muscle had a high } \\
\text { metabolic capacity (measured by } \\
\text { succinic oxidase levels). Successful } \\
\text { revascularisation reversed this to normal }\end{array}$ & $\begin{array}{l}\text { Paper recommends postoperative } \\
\text { exercise to retain high metabolic } \\
\text { capacity of the skeletal muscle }\end{array}$ \\
\hline $\begin{array}{l}\text { Askew } \\
2005[6]\end{array}$ & 29 & $\begin{array}{l}16 \text { PAD, } 13 \text { healthy } \\
\text { controls }\end{array}$ & $\begin{array}{l}\text { PAD severity } \\
\text { not given }\end{array}$ & $\begin{array}{l}\text { Medial head of } \\
\text { gastrocnemius }\end{array}$ & $\begin{array}{l}\text { Smaller type I fibres in SL }(p=0.08) \\
\text { Fewer type I fibres in SL }(p<0.05) \\
\text { Fewer capillary contacts in SL }(p<0.05) \text {, } \\
\text { Reduced glycogen stores. }\end{array}$ & $\begin{array}{l}\text { Type } 1 \text { fibre area, capillary to fibre } \\
\text { )ratio, capillary contacts to type I \& II } \\
\text { )fibres, type I glycogen stores were all } \\
\text { )positively correlated with exercise } \\
\text { tolerance in PAD ( } \mathrm{r} \text { not given, } \\
\mathrm{p}<0.05 \text { ), but not in health. }\end{array}$ \\
\hline $\begin{array}{l}\text { Clyne } \\
1982 \text { [7] }\end{array}$ & 93 & $\begin{array}{l}93 \text { subjects, } 63 \text { with } \\
\text { PAD, } \\
30 \text { healthy subjects } \\
\text { at post mortem } \\
129 \text { biopsies }\end{array}$ & IC and CLI & Gastrocnemius & $\begin{array}{l}\text { No change in fibre type distribution } \\
\text { between disease and health } \\
\text { Mean fibre area of type I in men with } \\
\text { IC }<\text { in health }(p<0.05) \\
\text { Reduction in II fibre area in SL }<\text { AL in } \\
\text { unilateral PAD patients }(p=0.02)\end{array}$ & $\begin{array}{l}\text { Evidence of denervation and } \\
\text { reinnervation more common as limb } \\
\text { severity increases } \\
\text { No change in capillary numbers? } \\
\text { ncompensated for by muscle fibre } \\
\text { shrinkage? }\end{array}$ \\
\hline $\begin{array}{l}\text { Hedburg } \\
1988[8]\end{array}$ & 14 & $\begin{array}{l}14 \text { maleLight and } \\
\text { electron microscopy } \\
\text { studies on all } \\
\text { biopsies }\end{array}$ & $\mathrm{IC}$ & $\begin{array}{l}\text { Medial head of } \\
\text { gastrocnemius }\end{array}$ & $\begin{array}{l}\text { Fibre necrosis } \\
\text { Regeneration } \\
\text { Angular fibres } \\
\text { Abundant connective tissue } \\
\text { Differences identified between surgical } \\
\text { candidates and those undergoing a SEP. }\end{array}$ & \\
\hline $\begin{array}{l}\text { Jansson } \\
1988[9]\end{array}$ & 7 & $\begin{array}{l}\text { Symptomatic limb } \\
\text { (SL) compared with } \\
\text { asymptomatic limb } \\
\text { (AL) }\end{array}$ & Unilateral IC & Gastrocnemius & $\begin{array}{l}\text { No difference between legs for muscle } \\
\text { fibre type, dimension, capillary density } \\
\text { or myoglobin content }\end{array}$ & $\begin{array}{l}\text { Claudication leg (symptomatic leg } \\
\text { SL) vs control leg (AL): } \\
\text { [citrate synthase] in SL > AL }\end{array}$ \\
\hline $\begin{array}{l}\text { Teravainen } \\
1977[10]\end{array}$ & $\begin{array}{l}21 \mathrm{pts}, \\
24 \mathrm{Bxs}\end{array}$ & $\begin{array}{l}\text { SL reviewed with } \\
\text { electron microscopy }\end{array}$ & $\begin{array}{l}\text { Unilateral } \\
\text { and bilateral } \\
\text { IC }\end{array}$ & Not stated & $\begin{array}{l}\text { Muscle fibre hypertrophy, atrophy, } \\
\text { autolytic or phagocytic fibres } \\
\text { Myofibrillar degeneration }\end{array}$ & $\begin{array}{l}\text { Pathological mitochondria } \\
\text { Excessive accumulation of glycogen } \\
\text { and lipofuscin } \\
\text { Positive correlation between degree } \\
\text { of pathological changes and } \\
\text { claudication severity }\end{array}$ \\
\hline $\begin{array}{l}\text { Angquist } \\
1980[11]\end{array}$ & 22 & $\begin{array}{l}\text { Symptomatic limb } \\
\text { (SL) compared with } \\
\text { asymptomatic limb } \\
\text { (AL) }\end{array}$ & Unilateral IC & $\begin{array}{l}\text { Bilateral } \\
\text { biopsies } \\
\text { Asymptomatic } \\
\text { leg acting as a } \\
\text { control } \\
\text { Biopsy site not } \\
\text { stated }\end{array}$ & $\begin{array}{l}\text { Volume of mitochondrial density } \\
\text { identified in all three fibre types. } \\
\text { Total mitochondrial density greater in } \\
\text { symptomatic leg compared to control } \\
\text { I > IIa > IIb for mitochondrial density in } \\
\text { both SL and AL } \\
\text { Difference in mitochondrial volume } \\
\text { density in type I fibres between SL and } \\
\text { AL co-variated with walking distance } \\
\text { Conclusion: fibre type specific } \\
\text { adaptations occur to in response to } \\
\text { ischaemia }\end{array}$ & \\
\hline
\end{tabular}


Table 2. Summary of muscle fibre types and metabolic activity.

\begin{tabular}{|c|c|c|c|}
\hline Fibre type & Type I & Type IIa & Type IIb \\
\hline Contraction time & Slow & Fast & V. Fast \\
\hline Size of motor neuron & Small & Large & V. Large \\
\hline Resistance to fatigue & High & Intermediate & Low \\
\hline Activity used for & Aerobic & Long term Anaerobic & Short term Anaerobic \\
\hline Force production & High & High & Low \\
\hline Mitochondrial density & High & Intermediate & Low \\
\hline Capillary density & High & Intermediate & Low \\
\hline Oxidative capacity & High & High & Low \\
\hline Glycolytic capacity & Low & High & High \\
\hline Major Storage Fuel & Tri-glycerides & Creatine Phosphate, Glycogen & Creatine Phosphate, Glycogen \\
\hline
\end{tabular}

\section{GLYCOGEN}

Depletion of glycogen stores in type II fibres does reduce the effectiveness of short burst activity [26], however training has a glycogen sparing effect in both fibre types (I \& II) in health. The use of glycogen loading has also been explored [4]; 6 patients with claudication underwent exercise testing, initially at baseline on a cycle ergometer, and then after two days of glucose loading. Muscle (vastus lateralis) biopsies pre- and post-glucose loading showed an increase in glycogen muscle stores, which correlated with a longer duration on the cycle ergometer. However, a corresponding improvement in walking distances was not identified, and the increased glycogen stores were a short-lived phenomenon. Carbohydrate loading pre-exercise in patients with peripheral arterial disease $(\mathrm{n}=11)$ and controls $(\mathrm{n}=8)$ has provided inconclusive evidence [27].

\section{L-CARNITINE}

During anaerobic metabolism, molecules other than glucose are broken down, e.g. L-carnitine. L-Carnitine is a peptide involved in fatty acid uptake by the mitochondria and its role has been explored in a double-blind cross-over study in claudicants $(n=20)$. The treatment group had a significant reduction in their post exercise lactate levels after three weeks of L-carnitine supplementation, quicker recovery and improved maximum walking distances, $174+/-63 \mathrm{~m}$ with placebo compared to $306+/-122 \mathrm{~m}$ in the L-carnitine group ( $\mathrm{p}<$ $0.01)[28]$.

\section{MUSCLE ARCHITECTURE}

Skeletal muscle architecture can be defined as "the arrangement of muscle fibres within a muscle relative to the axis of force generation [29]". The arrangement of the muscle fibres, their attachment to the bone (via tendons) and the pennation angle of the muscle (the fibre angle relative to the force-generating axis, reported to lie between $0^{\circ}-30^{\circ}$ ) are all factors which affect muscle architecture. Two important parameters are:

1) The physiological cross sectional area (PCSA), which is proportional to the maximal force of the muscle.

2) The muscle fibre length, this is between $20 \%-60 \%$ of the entire length of the muscle [30] and proportional to the muscle's active range (excursion).

No data currently exists on the relationship between pennation angles and fibre length within claudicants. The only data published on cross-sectional area has demonstrated no significant difference in health and PAD for this [31].

\section{MUSCLE FUNCTION}

Maximal voluntary contraction (MVC) is a measure of strength defined as the maximal exertion of force, in Newtons, kilograms or pounds. This can be assessed as a percentage of the maximum voluntary contraction, and is a method used within research. In health, exercise has been noted to increase the duration by which maximal muscle twitch tension is achieved [32].

The strength of patients with peripheral arterial disease compared to healthy counterparts as measured by the time taken to achieve $50 \%$ of MVC, was significantly lower in those with PAD compared to health [31] $(\mathrm{p}=$ 0.01 ). At $75 \% \mathrm{MVC}$, few patients with peripheral arterial disease who were able to achieve this degree of contraction.

\section{BLOOD FLOW}

Total blood flow to chronic ischaemic limbs has been investigated using intravenous radiolabelled isotopes and 
venous strain plethysmography. No demonstrable change in total limb blood flow was identified when compared with normal controls at rest [33,34] Focus has shifted to changes in regional blood flowusing radiolabelled $\mathrm{C}_{15} \mathrm{O}_{2}$ and $15 \mathrm{O}_{2}$ positron emission tomography (PET). In healthy non age-matched controls $(n=5)$, blood flow was concentrated at the vascular pedicle at rest and evenly distributed across the anterolateral compartment of the leg post exercise, in disease $(n=12)$, the pattern was more variable [35].

The clearance rate of radiolabelled intravenous isotopes from either hamstrings or gastrocnemius was greater in health than disease, both for aorto-iliac and sapheno-femoral artery stenoses in patients with PAD [36]. A clearance rate of over three minute is classed as prolonged, and identified in all patients with PAD both at rest [37] by radiolabelled isotopes and post exercise by near infrared spectroscopy (NIRS) [38]. The use of a sixmonth exercise regime improved clearance rates to less than 3 minutes in diseased legs. Adherence with the class was associated with improved walking distances. Maximal walking distances correlated with faster clearance rates $(r=0.64, p<0.0025)$ [38], time to achieve maximal blood flow post exercise $(r=-0.45, p<0.0025)$ [37] and the duration of hyperaemia $(\mathrm{r}=-0.77, \mathrm{p}<0.0005)$ $[37,39]$ Whilst total limb blood flow remains constant during exercise, flow to ischaemic areas increases when compared with baseline [40].

\section{CARDIAC \& LOWER LIMB MUSCLE}

Single photon emission computerised tomography (SPECT) with Tcm-sestamibi [41] has been used to assess the cardiovascular effect of exercise on patients with PAD $(n=16)$. Both cardiac and lower limb uptakes were evaluated: pre, during and post exercise on a ramp protocol $(10 \mathrm{~W} / \mathrm{min})$ cycle ergometer. Ten patients displayed a $25 \%$ cardiac perfusion defect, this decreased by $>10 \%$ with rest (indicating significant ischaemia), of concern only four of these complained of chest pain. Lower limb thigh uptake increased by $50 \%$ when changing from rest to exercise, but calf uptake did not. The ratio of uptake between the calves correlated strongly with Ankle Brachial Pressure Index (ABPI) $(r=0.71, \mathrm{p}<$ $0.01)$ [41].

\section{OXYGEN UPTAKE}

Oxygen uptake by lower limb muscle has also been measured by radio-labelled isotopes. Surprisingly, no significant difference was noted between health and disease for oxygen reuptake and oxygen extraction [42], but the rate of oxygen delivery was reduced, as measured by NIRS [31]. Exercise was noted to induce a fall in both muscle $\mathrm{pO}_{2}, \mathrm{pCO}_{2}$ and ankle blood pressure in those with
PAD $(n=37)$ compared to those with AAA $(n=5)$ and healthy controls $(n=4)$ [43]. In those with established ischaemia, daily exercise for 14 - 20 weeks did improve oxygen utilisation $(5.60+/-0.53 \mathrm{mumol} / \mathrm{min} / \mathrm{g}$ versus sedentary ischaemic mice; $3.66+/-0.026 \mathrm{mumol} / \mathrm{min} / \mathrm{g}$ ) [44].

\section{Arteriogenesis \& Collateralisation}

The improvement in ischaemic blood flow seen in studies has been postulated to be due to collateralisation via the process of arteriogenesis.

\section{ARTERIOGENESIS}

Arteriogenesis is the remodelling of pre-existing arterioles into larger calibre vessels (vessel diameter increases). By increasing the radius of the vessel, this is directly proportional to the flow through the vessel. Poiseuille's Law states that flow (Q) is related to the lumen's radius (r), length (L) of the vessel and viscosity ( $\dot{\eta})$ of the fluid and pressure gradient along the vessel $(\mathrm{P})$ : $\mathrm{Q}$ $=\pi \mathrm{r}^{4} \mathrm{P} / 8 \mathrm{~L} \dot{\eta}$.

Therefore in the ischaemic vessels, arteriogenesis may allow improved blood flow to specific ischaemic muscle groups via the collateral circulation. Arteriogenesis occurs in the presence of ischaemia with or without the use of exercise when compared to healthy controls. In rats with femoral artery ligation, the rate of vessel enlargement was $2 \%$ /day over 25 days [45], with no change occurring in the controls. Exercise has been foundto increase collateral blood flow by $43 \%$, in both young [ 40 , $45,46]$ and old models of ischaemia, compared to their sedentary counterparts; $67+/-10 \mathrm{ml} / \mathrm{min} / 100 \mathrm{~g}$ and 30 $+/-4.9 \mathrm{ml} / \mathrm{min} / 100 \mathrm{~g}$ respectively [47].

Arteriogenesis [48] is felt to be a more enduring exercise induced adaptation.

The mechanism for arteriogenesis differs from that of angiogenesis; however both have been explored in ischaemic models. In arteriogenesis, collateral vessels never become hypoxic, as they are always perfused and embedded in normo-oxic tissue, whereas angiogenesis is dependent on hypoxia and hypoxia inducible factor (HIF). Secondly, arteriogenesis is not reliant on proliferation of smooth muscle cells [49], an inflammatory environment or invasion of monocytes which are required in angiogenesis. E.g. For wound healing. The mechanism by which arteriogenesis occurs has been illustrated in Figure 2.

\section{SHEAR STRESS}

In health, during exercise, blood flow increases (see Figure 3), which causes shear stress on the vessel wall [48]. In ischaemic models, exercise led to a $60 \%$ im- 


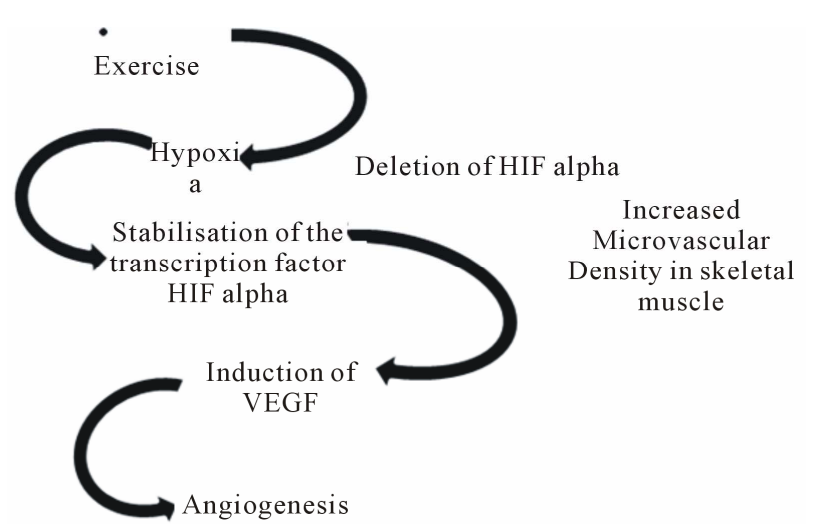

Figure 2. Flow Diagram of Postulated Mechanism for initiation of Angiogenesis [31].

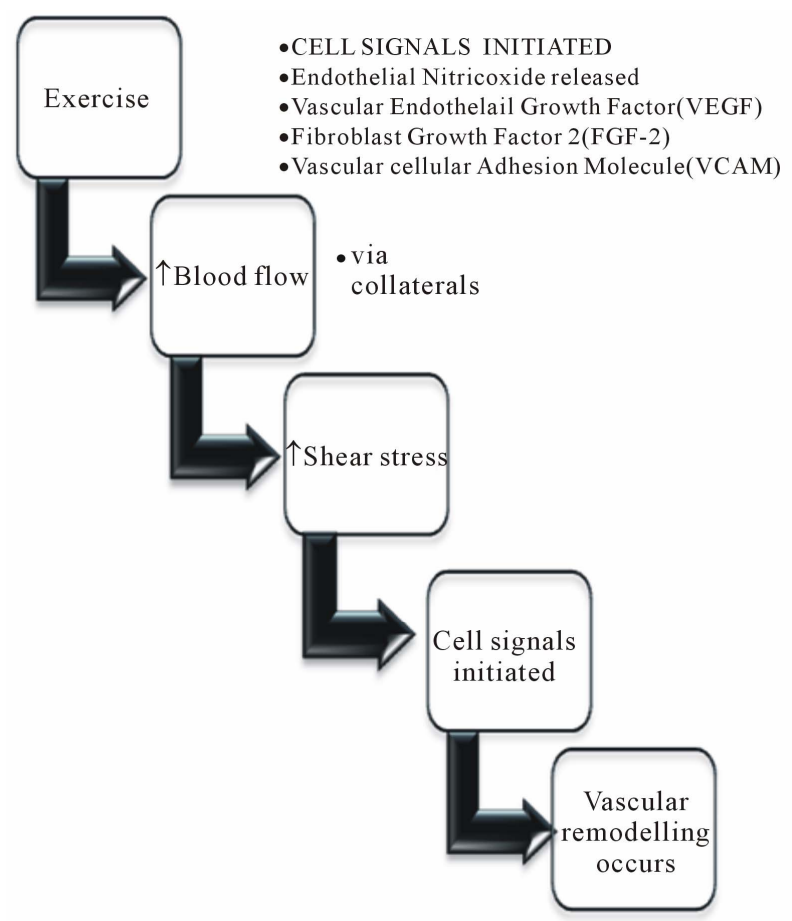

Figure 3. Flow diagram to illustrate the effect of exercise on vascular endothelium.

provement in muscle blood flow compared to healthy exercising rats. The partial improvement in ischaemic models was explored further by introducing artificial shear stress into the system.

Experimental studies forming collateral arteriovenous (AV) shunts in rabbit models [50,51]; found an improvement in maximum collateral conductance $\left(\mathrm{C}_{\max }\right)$. Schierlin get al identified that a femoral AV fistula resulted in a higher $\mathrm{C}_{\max }$ than just the use of angiogenic growth factors alone. The combination of both, AV shunts and intraarterial vascular endothelial growth factor (VEGF), demonstrated an improvement in blood flow comparable to that of normal non-ischaemic limbs [52].

\section{CELL SIGNALS}

The following cell signals are involved in vascular remodelling [46]:

- Exogenous angiogenic growth factors [48]

o VEGF; a diffusible endothelial cell-specific mitogen [53]

- First isolated in 1989 by Ferrara and Henzel

- Implicated in the cell signalling pathways for angiogenesis

o Fibroblast growth factor-2 (FGF-2)

- An endothelial mitogen

- Present in the basement membrane and subendothelial extracellular matrix of blood vessels

- Gene transfection

- Modulation of inflammation

\subsection{Vascular Endothelial Growth Factor (VEGF)}

Ischaemia induces arteriogenesis in the surrounding normal vasculature, the role of VEGF in this is uncertain.

\subsection{Fibroblast Growth Factor-2 (FGF-2)}

Intra-arterial infusions of FGF-2 have been found to increase calf muscle blood flow in rat models compared to placebo [54]. The use of FGF-2 for up to 28 days showed a significant improvement in collateral dependent blood flow, the improvement diminished by 42 days [54].

\subsection{Endothelial Nitric Oxide (eNO)}

Paradoxical results on the effect of nitric oxide on artreriogenesis have been noted, however the current overall consensus is that eNO is required in arteriogenesis [46, $49,55]$.

\section{ANGIOGENESIS \& CAPILLARISATION}

Angiogenesis-new vessel formation, is transient in healthy adults and primarily focused at the level of the capillaries and arterioles (diameter $<40$ microm) [48]. The mechanism associated with angiogenesis remains unclear and focused on a combination of VEGF, breakdown of the surrounding basement membranes (matrix metalloproteinases (MMPs)) and endothelial progenitor cells (EPCs from the bone marrow). Figure 2: Flow diagram of postulated mechanism for initiation of Angiogenesis [31].

Angiogenesis is a hypoxia-induced event resulting in an increase in muscle capillarisation, expressed as the number of capillaries per fibre. This was demonstrated by a higher capillary density in controls $\left(1.48 \mathrm{cap} / \mathrm{mm}^{2}\right)$, versus patients with fully occluded PAD $\left(1.54 \mathrm{cap} / \mathrm{mm}^{2}\right)$ and un-occluded PAD of their lower limbs (1.62 
$\mathrm{cap} / \mathrm{mm}^{2}$ ) [56]. Exercise results in increased metabolic demand and ischaemia leading to remodelling of muscle secondary to the oxidative stress it is under. Experiments exercising rats for a week demonstrated a threefold improvement in exercise ability, with an improved capillarity at 3 days (trained versus untrained; $5.70+/-0.10$ versus $4.68+/-0.11$ capillary contacts per fibre, $\mathrm{p}<$ $0.001)$ [57] and increased endothelial mitotic activity [58]. In humans with PAD $(n=11)$ similar results have been found; increased capillary number, capillary contacts with type IIa and x muscle fibres. A moderate positive correlation $(\mathrm{r}=0.69, \mathrm{p}<0.05)$ with increased pain free walking time was also noted [59].

\subsection{Vascular Endothelial Growth Factor (VEGF)}

In health, exercise induces an increase in VEGF mRNA $(p<0.001)$ and protein content $(p<0.05)$ compared with sedentary controls. The increase in VEGF was specifically found in type IIb myofibres, which may be explained by their increased susceptibility to hypoxia in comparison to type I fibres. VEGF has two receptors, one of which, receptor Flt-1 was found to have increased mRNA levels secondary to the hypoxic insult [60]. Receptor Flt-1 (VEGFR-1) has been demonstrated to affect the sprouting of new blood vessels. Murine models displayed an initial elevation in VEGF mRNA \& VEGFR-1 post ligation, however levels returned to normal by day 25. Overall, no sustained increase in VEGF mRNA or gene expression was found when compared to non-ischaemic healthy controls [46], but VEGFR-1 did remain two-fold higher with exercise training.

The only paper in PAD patients to link capillarisation with levels of angiogenic growth factors, demonstrated an increase in capillarisation, interleukin-6 (IL-6) $(n=19)$ and calf muscle VEGF mRNA $(\mathrm{n}=10)$ [61]; serum VEGF remained static. An increase in IL-6 is unsurprising as this cytokine is often up-regulated during exercise as it is postulated to modulate at a cellular level immunological and metabolic responses to exercise. Muscle fibre histology and walking distance were not assessed.

\subsection{Peroxisome-Proliferator-Activated Receptor-Gamma Co-Activator-1 (PGC1) Alpha}

Transcriptional co-activator PGC-1alpha is a dominant regulator of oxidative metabolism. It controls the activation of free fatty acid (FFA) oxidation and oxidative phosphorylation in skeletal muscle, through which it can allow conversion of type II muscle fibres to a more oxidative type (type I). In addition, it is necessary for induction of HIF independent angiogenesis [62].

In healthy mice, a two-fold increase in capillary density was found in the mid-portion of the quadriceps after
14 days of exercise training [62]. PGC1a knockout mice had no increase in capillary density after exercise; implicating PGC1a in the VEGF-exercise induced angiogenesis mechanism in skeletal muscle [62]. Interestingly, PGC1a has been noted to be repressed in humans and rodents with diabetes.

\section{MUSCLE METABOLISM: MITOCHONDRIA}

Exercise improves exercise capacity and lower limb blood flow in rats with lower limb ischaemia, however a $40 \%$ deficit remains when compared to age matched normal control rats [46]. This implies that the improvements secondary to exercise are not solely due to blood flow but an improvement in skeletal muscle metabolism $[45,63,64]$, just as in health.

Mitochondria are organelles within cells that convert glucose (in aerobic metabolism) or other substrates into ATP (energy for the cells). Any alteration in mitochondrial function will result in an alteration in the energy supply to the cell. In health improvements are noted in the metabolic oxidative capacity of muscle, namely citrate synthase and succinic dehydrogenase activity $[15$, $65]$.

Morphological changes in muscle metabolism include hyperplasia, proliferation, ballooning of the cristae and paracrystalline inclusions in skeletal muscle mitochondria. In addition, mitochondrial DNA damage has been noted. Structural and genetic defects in the mitochondria are deemed to be the cause of the energy dysfunction and utilization in peripheral arterial disease [66]. $25 \%$ of claudicants have been identified to have normal functioning mitochondria [66]. Therefore, a plethora of insults must account for the subsequent change in claudicating muscle. So far data has shown a correlation between walking distance and nuclear magnetic resonance spectroscopy but has not produced correlation between disease severity and walking capability [66]. This dichotomy has been supported by the work done by Zatina et al. looking at the effects of re-vascularisation on muscle metabolism. They showed that percutaneous revascularisation improved circulatory blood flow and symptoms, without a corresponding rapid improvement in the associated biochemical pathways [67].

\subsection{Organelles}

Muscle fibres require more ATP as their activity increases, and this ATP is generated by the mitochondria. The concentration of mitochondria in muscle fibre types has been reviewed by Angquist et al. Mitochondrial volume densities were compared in unilateral claudicant legs to their asymptomatic leg. An increase in volume density was identified in the affected limbs, which was 
also increased by proximal arterial occlusions of the lower limb compared to distal stenoses. Of interest, the mitochondrial content for IIa fibres correlated with walking distance and pain onset in disease, whilst in health it was type I fibres [11]. This may indicate that remodelling of the muscle occurs due to inactivity, or that reduced blood flow results in a reduced ability of the type I fibres to metabolise properly leading to cellular dysfunction and apoptosis, with a corresponding increase in type II fibres or fibre hypertrophy.

Both mitochondrial sub-populations, sub-sarcolemmal and inter-myofibrillar, increase in concentration in PAD compared with controls [68]. Although the increase in mitochondria should be associated with an increase in cellular metabolism, pathological mitochondria have also been reported. Therefore the cells metabolic activity may not correlate with mitochondrial volume density as it would in health. This requires further investigation, as does the effect of exercise on mitochondrial levels.

In ischaemic muscle, the enzyme cascades and efficiency of the organelle can be impaired, this has been identified in mitochondrial complexes I-V [17,69]. Complex I is determined by use of glutamate malate, II with succinate and IV with $\mathrm{N}, \mathrm{N}, \mathrm{N}^{\prime}, \mathrm{N}^{\prime}$-tetramethyl-p-phenylenediamine dihydrochloride ascorbate. It is important to remember that ischaemia alone has been sufficient to cause changes in mitochondrial pathways in these murine models. In humans, other risk factors (smoking, diabetes, hypertension, heart or lung disease) may add additional confounding factors to the function of mitochondrial complexes.

In rats, it was noted that mitochondrial dysfunction was a reversible phenomenon if those who subsequently had ischaemia were active beforehand with mitochondrial complex activities remaining at normal levels [69]. In humans with stenosed femoral arteries, exercise did demonstrate some improvement in mitochondrial activity; however improvements were greater in health.

\subsection{Enzymes}

ATP production may be used as a surrogate marker of mitochondrial activity and the muscles metabolic efficiency. The turnover rate of ATP has been found to be same between healthy controls and patients with PAD. The major difference seen was between the levels of oxyhaemaglobin, deoxygenated haemoglobin and ATP turnover rates $(\mathrm{p}=0.0003)$ [31].

Mitochondrial activity may be measured by citrate synthase, an enzyme involved in the citrate cycle for production of ATP, with higher levels found in ischaemic muscle compared to healthy controls [17]. Succinic oxidase activity, incorporation of glucose-carbon into glycogen, lipids, lactate and $\mathrm{CO}_{2}$ are also markers of metabolic activity. A significantly higher lactate-pyruvate ratio has also been noted in those with peripheral arterial disease [25] compared with healthy controls, as measured by popliteal venous and arterial blood [70].

Pre re-vascularisation an enhanced metabolic capacity was found in PAD patients $(\mathrm{n}=12)$, which diminished with successful re-vascularisation [5]. Chronic ischaemia increases muscle metabolism, but this is a reversible adaptation. Succinate dehydrogenase (SDH) activity was significantly higher in the IC [5] patients compared to the controls, but this reduced down to normal with successful revascularisation.

\subsection{Phosphocreatine (PCr)}

Phosphocreatine is a transport molecule and reservoir of high energy phosphate bonds. Its regeneration occurs solely in the mitochondria and is dependent on the oxygen supply and cells ability to perform oxidative phosphorylation [71]. Phosphorous (31P) nuclear magnetic resonance (NMR) spectroscopy has been used to determine calf muscle metabolism in patients with intermittent claudication as the phosphorus nuclei of DNA \& RNA, phospholipids and phosphoproteins are immobile and do not produce a measurable signal. The mobile phosphorus in ATP, ADP, $\mathrm{Pi}$, and $\mathrm{PCr}$ occurs in sufficient concentrations to yield a measurable, defined spectroscopy signal. (31P) NMRS can occur with time series of 36 seconds each, to allow a continuous monitoring of muscle metabolism. The test re-test reliability of the $\mathrm{PCr}$ recovery time constant was checked (controls $=8, \mathrm{PAD}=$ 3 ), the intra-class correlation coefficient was $r=0.95$ [71].

The median recovery time of phosphocreatine was prolonged in patients with PAD compared to health individuals [71,72]. The same difference was also noted for ADP, inorganic phosphate [66,72] and $\mathrm{pH}[72]$. The ratio of PCr/ATP $(p=0.03)$ and Pi/ATP $(p=0.04)$ were marginally, but significantly elevated $[71,72]$, this was attributed to a reduced level of ATP in patients, a finding contradicted by other groups who found no difference in the ratios at rest or during, or the muscle's post exercise $\mathrm{pH}(\mathrm{p}=0.07)[71]$.

Minimal changes in $\mathrm{pH}$ and $\mathrm{PCr}$ during exercise have been attributed to the type of exercise performed, namely oxidative, isometric exercise [72]. In health, the isometric (exercise which involves static muscle contraction without and change in the angle of the joint) and isotonic (exercise results in an alteration in the muscle length secondary to the movement of the body part) exercises [73] have been assessed, with isotonic exercise found to be more metabolically stressful than isometric exercise. Metabolic stress was attributed to the change in the Pi to $\mathrm{PCr}$ ratio from rest $(0.11+/-0.02)$ to exercise; isometric $(0.83+/-0.47)$ and isotonic $(1.40+/-0.59)$.

In those with peripheral arterial disease, walking ad- 
vice has often consisted of "exercise until it hurts, and then try and carry on through this". The difference between ischaemia (painful) inducing and non-ischaemic (non-painful) exercise was also explored. Post non-ischaemia inducing exercise no significant difference was found between healthy controls $(n=7)$ and those with a symptomatic arterial occlusion $(n=11)$ with respect to muscle $\mathrm{pH}$ and phosphocreatine levels [74]. However, in the presence of ischaemia, a prolonged recovery of reduced $\mathrm{PCr}$ and $\mathrm{pH}$ levels was noted in disease compared to health [74]. Given the continued fatiguability of the muscle, needle-biopsies have been performed; demonstrating a reduction in ATP and almost complete depletion of creatine phosphate during exercise [25].

Those with PAD have been shown to have a longer recovery time, compared to health, in keeping with the prolonged recovery of $\mathrm{PCr}$. These findings imply a reduced mitochondrial oxidative phosphorylation capacity in this cohort [75], as evidenced by prolonged $\mathrm{PCr}$ recovery times when patients with peripheral arterial disease were asked to exercise at increasing workloads [73].

From this work and the constant levels of intracellular ATP noted in both health and disease, it has been hypothesised that exercise induced hypoxia leads to the activation of the creatine kinase reaction, glycolysis, myokinase reaction and purine nucleotide cycle [72], which is sufficient to maintain ATP concentrations in spite of claudication pain. ATP synthesis was not the main rate-limiting factor, instead it was the impaired oxygen delivery to the muscle [31].

Re-vascularisation of patients with peripheral arterial disease, by either surgery or angioplasty, has shown a reduction in $31 \mathrm{P}$ uptake and quicker return to normal of muscle $\mathrm{pH}$ and $\mathrm{Pi} / \mathrm{PCr}$ ratio's [76,77]. Interestingly, no significant correlation has been made between ABPI and PCr or ADP change [66], or reactive blood flow to the muscle and Doppler or angiography or $\mathrm{PCr}$ [74]. $\mathrm{PCr}$ recovery times have been positively correlated with the degree of stenosis, as measured by Doppler $(r=0.739, \mathrm{p}$ $=0.019)$ and angiography $(\mathrm{r}=0.885, \mathrm{p}=0.005)$ [74].

\section{OTHER ENZYMES OF INTEREST}

Numerous other enzymes exist that have been explored in cardiovascular or peripheral vascular disease. The following section outlines the studies outcomes in brief and provides areas for future work.

\subsection{In Animal Models}

Heat shock proteins 72 are produced to combat protein related homeostatic oxidative stress. HSP72 protects skeletal muscle against contraction induced reactive oxygen species (ROS) formation. HSP72 has been identified to increase secondary to exercise in ischaemic Wistar rats compared to their sedentary ischaemic counterparts. When comparing ischaemic rats to their healthy age matched counter parts, HSP72 levels were not altered by ischaemia in sedentary rats. However levels did alter, with an increased level of HSP72 in the ischaemic exercised group over the healthy exercised group. In reverse to this, the oxidative capacity of the muscle was lower in the ischaemic exercised group compared with the healthy group [78].

Apolipoprotein $\mathrm{E}$ is a protein that combines with fats to form lipoproteins. ApoE is a major component of VLDL, and transports cholesterol to the liver for processing. Of the three main alleles, e2, e3 and e4, e3 is the most common one available. One copy of the apo e4 allele results in an increased risk of atherosclerosis, whilst e2 is associated with an increased risk of hyperlipoproteinemia. Plaque stability in apoE $-/-$ mice who underwent 6 months of swimming exercise was compared to control apoE-/- mice. Exercised mice developed a more stable plaque phenotype as shown by decreased macrophage and increased smooth muscle content [79].

\subsection{In Human Studies}

In healthy adults, six weeks of exercise has resulted in a training adaptation on the mitochondrial uncoupling protein 3 (UCP3) [80], the effect in PAD has not been explored. In patients with ischaemic heart disease or hypertension, the metabolic activity of the muscle [81] has been explored with focus on the concentration of the coenzyme Q10, skeletal muscle mitochondrial electron carriers and concentrations of the antioxidant ubiquinone. In both IHD and hypertension, a reduction in all three markers of muscle metabolism was noted. The ratio of CoQ10 to type I fibre \% is inversely related to the risk of metabolic trauma [81] to the cells; a relationship that was present in IHD patients, but not hypertensive patients.

\section{PHARMACOLOGICAL TARGETS}

The effect of pharmacological targets on muscle physiology and blood flow has also been explored in patients with PAD. A previous treatment of claudication involved percutaneous vascular neurolysis (neurolytic lumbar sympathetic blockade). Using NMR spectroscopy, the increase in walking distance was noted to correlate with the rate of $\mathrm{PCr}$ regeneration post neurolysis [82]. In 10 patents with PAD given either intravenous administration of $200 \mathrm{mg}$ pentoxifylline or physiological saline solution (placebo), a significant increase in median $\mathrm{pO}_{2}$ at twenty minutes post exercise in the treatment group was shown. Pentoxifylline led to homogeneous capillary perfusion, with better reactive hyperemia post exercise and improved tissue oxygenation. 
Proprionyl-L-carnitine (PLC) was provided to patients daily for three months and any subsequent improvements in walking distance were measured by treadmill test in conjunction to NMR 31P spectroscopy to determine changes in energy efficiency and metabolism within the muscle. Although the PLC did not result in a significant increase in MWD, it did demonstrate a change in muscle metabolism of $30 \%$ in those who had the PLC compared to those who had not.

In the PLC group, the degree of $\mathrm{pH}$ reduction with exercise reduced $(p=0.04)$, the recovery half-time for $\mathrm{PCr}$ levels was negatively correlated with MWD $(\mathrm{r}-0.91, \mathrm{p}$ $=0.01$ ) [83]. A separate study using $300 \mathrm{mg}$ PLC infusions; three times over a period of 33 days to 26 claudicants; also noted an improvement in skeletal muscle activity. Capillaroscopy also demonstrated an improvement in angio-architecture (which was not defined), however functional improvements in walking distance were also found (although it was not stated whether this improvement was of significance) [84].

Other medications that have been explored for any additional benefit in PAD have included regular cardiovascular anti-hypertensives and vitamin C. Angiotensin converting enzyme inhibitors (ACE-i) have been considered to improve arteriogenesis; Ren et al identified that low dose quinapril $(3 \mathrm{mg} / \mathrm{kg})$ reduced ACE activity whilst increasing collateral blood flow to the calf muscle compared to controls. In addition to the improved calf muscle blood flow, gene expression of pro-angiogenic phenotype was also detected by real time reverse transcriptase polymerase chain reaction (RTPCR) [85]. Alpha-1 blockers have been demonstrated to improve blood flow by $40 \%$ in healthy, non-occluded limbs. In ischaemic limbs a decreased muscle conductance and collateral blood flow has been found, whilst collateral circuit's resistance remained unaltered [86]. In the ischaemic model, a decrease in blood flow and conductance occurred secondary to alpha-2 blockade - which did not occur in health. Rauwolscine also resulted in a significantly increased resistance in the distal limb of the collateral circuit [86].

The evidence from animal models demonstrated that ischaemic muscle was able to adapt and improve its aerobic functional ability. Nicholson et al also looked at the effect of calcium channel blockers and potassium channel agonists. They identified an improvement in skeletal blood flow and metabolism with the use of potassium channel agonists [87].

Ascorbic acid $(100 \mathrm{mg} / \mathrm{kg})$ was administered intraperitoneally to Wistar rats for 14 days to identify whether improvement in muscle performance and architecture was gained over exercise or ischaemia alone. Whilst exercise resulted in severe structural damage and reduced cross-sectional area, there was no significant reduction in tetanic tension. The addition of vitamin $\mathrm{C}$ did not im- prove this greatly, but did preserve the muscle tetanic tension in the extensor digitorum longus and soleus [88].

\section{SUMMARY}

The evidence based is wide-ranging and disparate. The numerous studies have identified numerous areas that alter due to PAD and exercise. Whilst alterations in muscle fibre type remain inconclusive, those of changes in regional blood flow are more consistent. A further focus on the metabolic changes occurring at a cellular level shows areas of interest that may become potential future therapeutic targets. No single identifiable focus has been identified that is the factor leading to an improvement in walking distances and symptom control in patients with PAD.

At present the physiological changes secondary to exercise that lead to better walking distances remain only partially explored with many excellent targets for research studies remaining.

\section{REFERENCES}

[1] Lambert, J. and Lambert, P.J. (1967) Untoward hemodynamic effects of intra-arterial injections of vasodilator drugs on the muscle circulation in the dog hind limb with experimental arterial occlusion. Angiology, 18, 415-27. doi: $10.1177 / 000331976701800702$

[2] Link, R.P., Pedersoli, W.M. and Safanie, A.H. (1972) Effect of exercise on development of atherosclerosis in swine. Atherosclerosis, 15, 107-22. doi:10.1016/0021-9150(72)90044-5

[3] Makitie, J. and Teravainen, H. (1977) Histochemical changes in striated muscle in patients with intermittent claudication. Archives of Pathology \& Laboratory Medicine, 101, 658-663.

[4] Dahllof, A.G., Holm, J., Kral, J. and Schersten, T. (1975) The relationship between glycogen content of leg muscles and working capacity in patients with intermittent claudication. Acta Chirurgica Scandinavica, 141, 329-332.

[5] Holm, J., Dahllof, A.G. and Schersten, T. (1975) Metabolic activity of skeletal muscle in patients with peripheral arterial insufficiency. Effect of arterial reconstructive surgery. Scandinavian Journal of Clinical \& Laboratory Investigation, 35, 81-86. doi:10.3109/00365517509068009

[6] Askew, C.D., Green, S., Walker, P.J., Kerr, G.K., Green, A.A., Williams, A.D., et al. (2005) Skeletal muscle phenotype is associated with exercise tolerance in patients with peripheral arterial disease. Journal of Vascular Surgery, 41, 802-807. doi:10.1016/j.jvs.2005.01.037

[7] Clyne, C.A., Weller, R.O., Bradley, W.G., Silber, D.I., O'Donnell Jr., T.F. and Callow, A.D. (1982) Ultrastructural and capillary adaptation of gastrocnemius muscle to occlusive peripheral vascular disease. Surgery, 92, 434440.

[8] Hedberg, B., Angquist, K.A. and Sjostrom, M. (1988) 
Peripheral arterial insufficiency and the fine structure of the gastrocnemius muscle. International Journal of Angiology, 7, 50-59.

[9] Jansson, E., Johansson, J., Sylven, C. and Kaijser, L. (1988) Calf muscle adaptation in intermittent claudication. Side-differences in muscle metabolic characteristics in patients with unilateral arterial disease. Clinical Physiology, 8, 17-29.

[10] Teravainen, H. and Makitie, J. (1977) Striated muscle ultrastructure in intermittent claudication. Archives of Pathology \& Laboratory Medicine, 101, 230-235.

[11] Angquist, K.A. and Sjostrom, M. (1980) Intermittent claudication and muscle fiber fine structure: Morphometric data on mitochondrial volumes. Ultrastructural $\mathrm{Pa}$ thology, 1, 461-470. doi:10.3109/01913128009140552

[12] Schocke, M.F.H., Esterhammer, R., Ostermann, S., Santner, W., Gorny, O., Fraedrich, G., et al. (2006) High-energy phosphate metabolism during calf ergometry in patients with isolated aorto-iliac artery stenoses. Investigative Radiology, 41, 874-882. doi:10.1097/01.rli.0000246148.09129.42

[13] Eto, D., Yamano, S., Kasashima, Y., Sugiura, T., Nasu, T., Tokuriki, M., et al. (2003) Effect of controlled exercise on middle gluteal muscle fibre composition in Thoroughbred foals. Equine Veterinary Journal, 35, 676-680. doi: $10.2746 / 042516403775696276$

[14] Lane, R.J., Barrett, M.C., Woodrow, D., Moss, J., Fletcher, R. and Archard, L.C. (1998) Muscle fibre characteristics and lactate responses to exercise in chronic fatigue syndrome. Journal of Neurology, Neurosurgery \& Psychiatry, 64, 362-367. doi:10.1136/jnnp.64.3.362

[15] Brackenbury, J.H. and Holloway, S.A. (1991) Age and exercise effects on mitochondrial density and capillary fibre ratio in bird leg muscle. British Poultry Science, 32, 645-653. doi:10.1080/00071669108417389

[16] Dingboom, E.G., Dijkstra, G., Enzerink, E., van Oudheusden, H.C. and Weijs, W.A. (1999) Postnatal muscle fibre composition of the gluteus medius muscle of Dutch Warmblood foals; maturation and the influence of exercise. Equine Veterinary Journal, 31, 95-100. doi:10.1111/j.2042-3306.1999.tb05320.x

[17] Pipinos, I.I., Swanson, S.A., Zhu, Z., Nella, A.A., Weiss, D.J., Gutti, T.L., et al. (2008) Chronically ischemic mouse skeletal muscle exhibits myopathy in association with mitochondrial dysfunction and oxidative damage. American Journal of Physiology-Regulatory Integrative and Comparative Physiology, 295, R290-R296. doi:10.1152/ajpregu.90374.2008

[18] Hain, B.A., Dodd, S.L. and Judge, A.R. (2011) IBalpha degradation is necessary for skeletal muscle atrophy associated with contractile claudication. American Journal of Physiology-Regulatory Integrative and Comparative Physiology, 300, R595-R604. doi:10.1152/ajpregu.00728.2010

[19] Egan, B., Carson, B.P., Garcia-Roves, P.M., Chibalin, A.V., Sarsfield, F.M., Barron, N., et al. (2010) Exercise intensity-dependent regulation of peroxisome proliferator-activated receptor coactivator-1 mRNA abundance is associated with differential activation of upstream signal- ling kinases in human skeletal muscle. The Journal of Physiology, 588, 1779-1790.

doi:10.1113/jphysiol.2010.188011

[20] Daugaard, J.R. and Richter, E.A. (2001) Relationship between muscle fibre composition, glucose transporter protein 4 and exercise training: possible consequences in non-insulin-dependent diabetes mellitus. Acta Medica Scandinavica, 171, 267-276. doi:10.1046/j.1365-201x.2001.00829.x

[21] Frisk-Holmberg, M., Jorfeldt, L., Juhlin-Dannfelt, A. and Karlsson, J. (1981) Leg blood flow during exercise in man in relation to muscle fibre composition. Acta Medica Scandinavica, 112, 339-342. doi:10.1111/j.1748-1716.1981.tb06825.x

[22] Hammarsten, J., Bylund-Fellenius, C. and Holm, J. (1980) Capillary supply and muscle fibre types in patients with intermittent claudication: Relationships between morphology and metabolism. European Journal of Clinical Investigation, 10, 301-305. doi:10.1111/j.1365-2362.1980.tb00037.x

[23] Green, H.J., Smith, D., Murphy, P. and Fraser, I. (1990) Training-induced alterations in muscle glycogen utilization in fibre-specific types during prolonged exercise. Canadian Journal of Physiology and Pharmacology, 68, 1372-1376. doi:10.1139/y90-208

[24] Magal, M., Dumke, C.L., Urbiztondo, Z.G., Cavill, M.J., Triplett, N.T., Quindry, J.C., et al. (2010) Relationship between serum creatine kinase activity following exercise-induced muscle damage and muscle fibre composition. Journal of Sports Science and Medicine, 28, 257 266.

[25] Pernow, B., Saltin, B., Wahren, J., Cronestrand, R. and Ekestroom, S. (1975) Leg blood flow and muscle metabolism in occlusive arterial disease of the leg before and after reconstructive surgery. Clinical Science \& Molecular Medicine, 49, 265-275.

[26] Karlsson, J., Sjodin, B., Jacobs, I. and Kaiser, P. (1981) Relevance of muscle fibre type to fatigue in short intense and prolonged exercise in man. Ciba Foundation Symposium, 82, 59-74.

[27] Barker, G.A., Green, S. and Walker, P.J. (2004) Effect of carbohydrate supplementation on walking performance in peripheral arterial disease: A preliminary physiologic study. Journal of Vascular Surgery, 40, 932-938. doi:10.1016/i.jvs.2004.07.047

[28] Brevetti, G., Chiariello, M., Ferulano, G., Policicchio, A., Nevola, E., Rossini, A., et al. (1988) Increases in walking distance in patients with peripheral vascular disease treated with L-carnitine: A double-blind, cross-over study. Circulation, 77, 767-773. doi:10.1161/01.CIR.77.4.767

[29] Lieber, R.L. (1993) Skeletal muscle architecture: Implications for muscle function and surgical tendon transfer. Journal of Hand Therapy, 6, 105-113. doi:10.1016/S0894-1130(12)80291-2

[30] Lieber, R.L. and Friden, J. (2000) Functional and clinical significance of skeletal muscle architecture. Muscle Nerve, 23, 1647-1666.

doi:10.1002/1097-4598(200011)23:11<1647::AID-MUS1 $>3.0 . \mathrm{CO} ; 2-\mathrm{M}$ 
[31] Kemp, G.J., Roberts, N., Bimson, W.E., Bakran, A., Harris, P.L., Gilling-Smith, G.L., et al. (2001) Mitochondrial function and oxygen supply in normal and in chronically ischemic muscle: A combined 31P magnetic resonance spectroscopy and near infrared spectroscopy study in vivo. Journal of Vascular Surgery, 34, 1103-1110. doi:10.1067/mva.2001.117152

[32] Nicholson, C.D., Angersbach, D. and Wilke, R. (1992) The effect of physical training on rat calf muscle, oxygen tension, blood flow, metabolism and function in an animal model of chronic occlusive peripheral vascular disease. International Journal of Sports Medicine, 13, 60-64. doi:10.1055/s-2007-1021236

[33] Yang, H.T., Ogilvie, R.W. and Terjung, R.L. (1991) Low-intensity training produces muscle adaptations in rats with femoral artery stenosis. Journal of Applied Physiology, 71, 1822-1829.

[34] Afaq, A., Montgomery, P.S., Scott, K.J., Blevins, S.M., Whitsett, T.L. and Gardner, A.W. (2008) The effect of hypercholestrolemia on calf muscle hemoglobin oxygen saturation in patients with intermittent claudication. Angiology, 59, 534-541.

[35] Depairon, M., De Landsheere, C., Merlo, P., Del Fiore, G., Quaglia, L., Peters, J.M., et al. (1988) Effect of exercise on the leg distribution of $\mathrm{C} 15 \mathrm{O} 2$ and $15 \mathrm{O} 2$ in normals and in patients with peripheral ischemia: A study using positron tomography. International Journal of Angiology, 7, 254-257.

[36] Appleberg, M. and Lewis, J.D. (1975) Evaluation of aorto-iliac disease with Doppler ultrasound and isotope clearance techniques. South African Medical Journal, 49, 1744-1746.

[37] Alpert, J.S., Larsen, O.A. and Lassen, N.A. (1969) Exercise and intermittent claudication. Blood flow in the calf muscle during walking studied by the xenon-133 clearance method. Circulation, 39, 353-359. doi:10.1161/01.CIR.39.3.353

[38] McCully, K.K., Halber, C. and Posner, J.D. (1994) Exercise-induced changes in oxygen saturation in the calf muscles of elderly subjects with peripheral vascular disease. Journal of Gerontology, 49, B128-B134. doi:10.1093/geronj/49.3.B128

[39] Dorigo, B., Bartoli, V., Grisillo, D., Beconi, D. and Zanini, A. (1980) Exercise hyperemia for the study of peripheral circulation. Angiology, 31, 50-57. doi: $10.1177 / 000331978003100108$

[40] Weiss, T., Fujita, Y., Kreimeier, U. and Messmer, K. (1992) Effect of intensive walking exercise on skeletal muscle blood flow in intermittent claudication. Angiology, 43, 63-71. doi:10.1177/000331979204300108

[41] Bostrom, P.A., Diemer, H., Leide, S., Lilja, B. and Bergqvist, D. (1993) 99Tcm-sestamibi uptake in the leg muscles and in the myocardium in patients with intermittent claudication. Angiology, 44, 971-976. doi: $10.1177 / 000331979304401208$

[42] Depairon, M., Depresseux, J.C., De, C., Merlo, P., Del, G., Quaglia, L., et al. (1988) Quantitation of regional muscle blood flow and oxygen uptake in peripheral arterial insufficiency using positron emission tomography.
Journal des Maladies Vasculaires, 13, 107-115.

[43] Jussila, E., Niinikoski, J. and Inberg, M.V. (1979) Tissue gas tensions in the calf muscles of patients with lower limb arterial ischaemia. Scandinavian Cardiovascular Journal, 13, 77-82. doi:10.3109/14017437909101791

[44] Erney, T.P., Mathien, G.M. and Terjung, R.L. (1991) Muscle adaptations in trained rats with peripheral arterial insufficiency. American Journal of Physiology-Heart and Circulatory Physiology, 260, H445-H452.

[45] Prior, B.M., Lloyd, P.G., Ren, J., Li, H., Yang, H.T., Laughlin, M.H., et al. (2004) Time course of changes in collateral blood flow and isolated vessel size and gene expression after femoral artery occlusion in rats. American Journal of Physiology Heart Circulatory Physiology, 287, H2434-H2447. doi:10.1152/ajpheart.00398.2004

[46] Yang, H.T., Laughlin, M.H. and Terjung, R.L. (2000) Prior exercise training increases collateral-dependent blood flow in rats after acute femoral artery occlusion. American Journal of Physiology Heart Circulatory Physiology, 279, H1890-H1897.

[47] Yang, H.T., Ogilvie, R.W. and Terjung, R.L. (1995) Training increases collateral-dependent muscle blood flow in aged rats. American Journal of Physiology Heart and Circulatory Physiology, 268, H1174-H1180.

[48] Kojda, G. and Hambrecht, R. (2005) Molecular mechanisms of vascular adaptations to exercise. Physical activeity as an effective antioxidant therapy? Cardiovasc Research, 67, 187-197. doi:10.1016/j.cardiores.2005.04.032

[49] Troidl, K., Ruding, I., Cai, W.J., Mucke, Y., Grossekettler, L., Piotrowska, I., et al. (2009) Actin-binding rho activating protein $(\mathrm{Abra})$ is essential for fluid shear stressinduced arteriogenesis. Arteriosclerosis Thrombosis Vascular Biology, 29, 2093-2101. doi:10.1161/ATVBAHA.109.195305

[50] Schierling, W., Troidl, K., Troidl, C., Schmitz-Rixen, T., Schaper, W. and Eitenmuller, I.K. (2009) The role of angiogenic growth factors in arteriogenesis. Journal of Vascular Research, 46, 365-374. doi:10.1159/000189797

[51] Schierling, W., Troidl, K., Mueller, C., Troidl, C., Wustrack, H., Bachmann, G., et al. (2009) Increased intravascular flow rate triggers cerebral arteriogenesis. Journal of Cerebral Blood Flow \& Metabolism, 29, 726-737. doi: $10.1038 /$ jcbfm.2008.165

[52] Prior, B.M., Ren, J., Terjung, R.L. and Yang, H.T. (2011) Significant, but limited collateral blood flow increases occur with prolonged training in rats with femoral artery occlusion. Journal of Physiology and Pharmacology, 62, 197-205.

[53] Ferrara, N. (2004) Vascular endothelial growth factor: Basic science and clinical progress. Endocrine Reviews, 25, 581-611. doi:10.1210/er.2003-0027

[54] Allen, L.A., Terjung, R.L. and Yang, H.T. (2006) Exogenous basic fibroblast growth factor increases collateral blood flow in female rats with femoral artery occlusion. Journal of Cardiovascular Pharmacology, 47, 146154. doi:10.1097/01.fjc.0000199145.54220.58

[55] Troidl, K., Tribulova, S., Cai, W.J., Eitenmuller, I., Wustrack, H., Schierling, W., et al. (2009) Effects of endoge- 
nous NO and of DETA NONOate in Arteriogenesis. Journal of cardiovascular pharmacology, 2, 153-160.

[56] Henriksson, J., Nygaard, E., Andersson, J. and Eklof, B. (1980) Enzyme activities, fibre types and capillarization in calf muscles of patients with intermittent claudication. Scandinavian Journal of Clinical and Laboratory Investigation, 40, 361-369. doi:10.3109/00365518009092656

[57] Yang, H.T., Ogilvie, R.W. and Terjung, R.L. (1994) Peripheral adaptations in trained aged rats with femoral ar-tery stenosis. Circulation Research, 74, 235-243. doi:10.1161/01.RES.74.2.235

[58] Deschenes, M.R. and Ogilvie, R.W. (1999) Exercise stimulates neovascularization in occluded muscle without affecting bFGF content. Medicine \& Science in Sports \& Exercise, 31, 1599-1604. doi:10.1097/00005768-199911000-00016

[59] Wang, J., Zhou, S., Bronks, R., Graham, J. and Myers, S. (2009) Effects of supervised treadmill walking training on calf muscle capillarization in patients with intermittent claudication. Angiology, 60, 36-41. doi:10.1177/0003319708317337

[60] Birot, O.J., Koulmann, N., Peinnequin, A. and Bigard, X.A. (2003) Exercise-induced expression of vascular endothelial growth factor mRNA in rat skeletal muscle is dependent on fibre type. Journal of Physiology, 552, 213221. doi:10.1113/jphysiol.2003.043026

[61] Palmer-Kazen, U., Religa, P. and Wahlberg, E. (2009) Exercise in patients with intermittent claudication elicits signs of inflammation and angiogenesis. European Journal of Vascular and Endovascular Surgery, 38, 689-696. doi:10.1016/j.ejvs.2009.08.005

[62] Chinsomboon, J., Ruas, J., Gupta, R.K., Thom, R., Shoag, J., Rowe, G.C., et al. (2009) The transcriptional coactivator PGC-1alpha mediates exercise-induced angiogenesis in skeletal muscle. Proceeding of the National Academy of Sciences of the United States of America, 106, 21401-21406. doi:10.1073/pnas.0909131106

[63] Mathien, G.M. and Terjung, R.L. (1990) Muscle blood flow in trained rats with peripheral arterial insufficiency. American Journal of Physiology-Heart and Circulatory Physiology, 258, H759-H765.

[64] Mathien, G.M. and Terjung, R.L. (1986) Influence of training following bilateral stenosis of the femoral artery in rats. American Journal of Physiology, 250, H1050H1059.

[65] Melichna, J., Mackova, E.V., Semiginovsky, B., Tolar, M., Stichova, J., Slavicek, A., et al. (1987) Effect of exercise on muscle fibre composition and enzyme activities of skeletal muscles in young rats. Physiol Bohemoslov, 36, 321-328.

[66] Pipinos, I.I., Shepard. A.D., Anagnostopoulos, P.V., Katsamouris, A. and Boska, M.D. (2000) Phosphorus 31 nuclear magnetic resonance spectroscopy suggests a mitochondrial defect in claudicating skeletal muscle. Journal of Vascular Surgery, 31, 944-952. doi:10.1067/mva.2000.106421

[67] Zatina, M.A., Berkowitz, H.D., Gross, G.M., Maris, J.M. and Chance, B. (1986) 31P nuclear magnetic resonance spectroscopy: Noninvasive biochemical analysis of the ischemic extremity. Journal of Vascular Surgery, 3, 411420.

[68] Elander, A., Sjostrom, M., Lundgren, F., Schersten, T. and Bylund-Fellenius, A.C. (1985) Biochemical and morphometric properties of mitochondrial populations in human muscle fibres. Clinical Science (Lond), 69, 153164.

[69] Thaveau, F., Zoll, J., Rouyer, O., Chafke, N., Kretz, J.G., Piquard, F., et al. (2007) Ischemic preconditioning specifically restores complexes I and II activities of the mitochondrial respiratory chain in ischemic skeletal muscle. Journal of Vascular Surgery, 46, 541-547. doi:10.1016/j.jvs.2007.04.075

[70] Maass, U. (1983) Experimental design in angiological clinical therapeutic research, inter- and intraindividual comparison in patients with intermittent claudication. [German] Zur Methodik in der Angiologisch-TherapeutischKlinischen Forschung. inter- und Intraindividueller Vergleich bei Arterieller Verschlusskrankheit. Fortschritte der Medizin, 101, 1831-1837.

[71] Kramer, C.M. (2007) Peripheral arterial disease assessment: Wall, perfusion, and spectroscopy. Topics in Magnetic Resonance Imaging, 18, 357-369. doi:10.1097/rmr.0b013e31815d064c

[72] Rexroth, W., Semmler, W., Guckel, F., Stadlander, M., Weicker, H., Hild, R., et al. (1989) Assessment of muscular metabolism in peripheral arterial occlusive disease using $<$ sup $>31</$ sup $>$ P nuclear magnetic resonance spectroscopy. Klinische Wochenschrift, 67, 804-812. doi:10.1007/BF01725196

[73] Schunk, K., Kersjes, W., Schadmand-Fischer, S., Thelen, M. (1997) Dynamic 31phosphorus magnetic resonance spectroscopy of the quadriceps muscle: Metabolic changes resulting from two different forms of exercise. Rofo, 166, 317-323. doi:10.1055/s-2007-1015432

[74] Keller, U., Oberhansli, R., Huber, P., Widmer, L.K., Aue, W.P., Hassink, R.I., et al. (1985) Phosphocreatine content and intracellular $\mathrm{pH}$ of calf muscle measured by phosphorus NMR spectroscopy in occlusive arterial disease of the legs. European Journal of Clinical Investigation, 15, 382-388. doi:10.1111/j.1365-2362.1985.tb00289.x

[75] Schunk, K., Romaneehsen, B., Mildenberger, P., Kersjes, W., Schadmand-Fischer, S. and Thelen, M. (1997) Dynamic phosphorus-31 magnetic resonance spectroscopy in arterial occlusive disease. Correlation with clinical and angiographic findings and comparison with healthy volunteers. Investigative Radiology, 32, 651-659. doi:10.1097/00004424-199711000-00001

[76] Schunk, K., Romaneehsen, B., Dahm, M., Dietz, U., Kersjes, W., Schadmand-Fischer, S., et al. (1997) Dynamic 31-phosphorus magnetic resonance spectroscopy of the m. quadriceps: Therapy-induced changes in arterial occlusive disease. Rofo, 167, 139-146. doi:10.1055/s-2007-1015507

[77] Schunk, K., Romaneehsen, B., Rieker, O., Duber, C., Kersjes, W., Schadmand-Fischer, S., et al. (1998)Dynamic phosphorus-31 magnetic resonance spectroscopy in arterial occlusive disease: Effects of vascular therapy on spectroscopic results. Investigative Radiology, 33, 329- 


\section{5. doi:10.1097/00004424-199806000-00003}

[78] Ecochard, L., Lhenry, F., Sempore, B. and Favier, R. (2000) Skeletal muscle HSP72 level during endurance training: Influence of peripheral arterial insufficiency. Pflugers Archiv, 440, 918-924. doi:10.1007/s004240000362

[79] Pellegrin, M., Miguet-Alfonsi, C., Bouzourene, K., Aubert, J.F., Deckert, V., Berthelot, A., et al. (2009) Longterm exercise stabilizes atherosclerotic plaque in ApoE knockout mice. Medicine \& Science in Sports \& Exercise, 41, 2128-2135. doi:10.1249/MSS.0b013e3181a8d530

[80] Russell, A.P., Somm, E., Praz, M., Crettenand, A., Hartley, O., Melotti, A., et al. (2003) UCP3 protein regulation in human skeletal muscle fibre types I, IIa and IIx is dependent on exercise intensity. Journal of Physiology, 550, 855-861. doi:10.1113/jphysiol.2003.040162

[81] Karlsson, J., Diamant, B., Folkers, K. and Lund, B. (1991) Muscle fibre types, ubiquinone content and exercise capacity in hypertension and effort angina. Annals Medicine, 23, 339-344. doi:10.3109/07853899109148070

[82] Melchert, U.H., Brinkmann, G., Forger, K., Gleim, M., Wunsch-Binder, F., Maier, C., et al. (1992) In vivo 31phosphorus MR spectroscopy of the calf musculature in arterial occlusive diseases. [German] In-vivo-31Phosphor MR-Spektroskopie der Wadenmuskulatur bei arterieller VerschluBkrankheit. RoFo, 156, 346-352. doi:10.1055/s-2008-1032899

[83] Taylor, D.J., Amato, A., Hands, L.J., Kemp, G.J., Ramas- wami, G., Nicolaides, A., et al. (1996) Changes in energy metabolism of calf muscle in patients with intermittent claudication assessed by $31 \mathrm{P}$ magnetic resonance spectroscopy: A phase II open study. Vascular Medicine, 1, 241-245.

[84] Allegra, C., Antignani, P.L., Schachter, I., Koverech, A., Messano, M. and Virmani, A. (2008) Propionyl-L-carnitine in Leriche-Fontaine stage II peripheral arterial obstructive disease. Annals of Vascular Surgery, 22, 552558. doi:10.1016/j.avsg.2008.02.010

[85] Ren, J., Li, H., Prior, B.M. and Yang, H.T. (2008) Angiotensin converting enzyme inhibition enhances collateral artery remodeling in rats with femoral artery occlusion. The American Journal of the Medical Sciences, 335, 177-187. doi:10.1097/MAJ.0b013e318142b978

[86] Taylor, J.C., Li, Z., Yang, H.T., Laughlin, M.H. and Terjung, R.L. (2008) Alpha-adrenergic inhibition increases collateral circuit conductance in rats following acute occlusion of the femoral artery. Journal of Physiology, 586, 1649-1667. doi:10.1113/jphysiol.2007.149567

[87] Nicholson, C.D. (1996) Experimental models of chronic lower extremity arterial occlusive disease: Lessons for drug development. Vascular Medicine, 1, 43-49.

[88] Loizidis, T., Sioga, A., Economou, L., Frosinis, A., Kyparos, A., Zotou, A., et al. (2007) The role of ascorbic acid and exercise in chronic ischemia of skeletal muscle in rats. Journal of Applied Physiology, 102, 321-330. doi:10.1152/japplphysiol.00251.2005 